\title{
The Why of Sporadic Motor Neuron Disease - Many Factors, still a Mystery? \\ Bernd Krone ${ }^{1,2}$ \\ Center for Hygiene and Human Genetics, University Göttingen, Göttingen, Germany \\ ${ }^{2}$ Medical Laboratory, Kurt-Reuber-Haus, Herkulesstraße 34a, 34119 Kassel, Germany
}

Article Info

\section{Article Notes}

Received: 04/22/2016

Accepted: 05/18/2016

\section{${ }^{*}$ Correspondence:}

Dr. Bernd Krone

Center for Hygiene and Human Genetics

University Göttingen

Göttingen, Germany

Email: Bernd-Krone@t-online.de

(C) 2016 Krone B. This article is distributed under the terms of the Creative Commons Attribution 4.0 International License

\section{Keywords}

Human Endogenous Retroviruses

Neuromelanin

Iron

Beta-Carbolines

Melatonin

\section{ABSTRACT}

The sporadic forms of motor neuron diseases seem to depend on a multitude of factors that are, however, largely speculative. A main endogenous factor is seen in the enhanced expression of human endogenous retroviruses (HERVs). It is supposed that this is affecting the biogenesis of neuromelanin, in particular in the locus coeruleus. An altered neuromelanin with increased storage of metals and of precursors for toxins from food, respectively, might be of central importance. A hypothesis is described that is able to explain a number of observations and to understand roles and interactions of different factors. Toxins affecting the excitatory system are formed apparently within altered neuromelanin. Moreover, neuromelanin loaded with metal is also a microenvironment where pathological variants of proteins such as of alphasynuclein are generated. Familial and toxin related forms of the diseases merge in formation and deposition of aberrant proteins and in a failure to destroy superoxide, thus increasing the harm from oxidative and nitrosative stress. This view might give some rational to revive investigations in methods for stabilization of storage and cautious squeezing out of metals and toxicants from neuromelanin, relying eventually on melatonin, iron chelators and chloroquine, respectively. 


\section{Introduction}

Motor neuron diseases comprise amyotrophic lateral sclerosis (ALS), progressive muscular atrophy, progressive bulbar palsy and pseudobulbar palsy ${ }^{1}$. They are neurodegenerative in nature and cause increasing disability and eventually, death. The etiology of these diseases is still largely obscure. Currently there is some progress in understanding of the more rare familial forms of the disease (for instance about $5-10 \%$ of the ALS cases) from associations with genetic mutations ${ }^{1}$. These mutations are localized in the genes for superoxide dismutase- $1^{1}$ (SOD1), and in the C9orf72 and TARDBP genes, respectively. SOD-1 is an enzyme involved in the handling of superoxide, a reactive oxygen species that is produced and is primarily of importance within mitochondria.

For the more frequent forms, sporadic motor neuron diseases (SMND), a view on the supposed etiology of the disease has to be searched apart from mutations ${ }^{2}$. This issue is difficult and largely speculative. Certainly the etiology of SMND is not simple and a mathematical analysis based on logarithm of incidence and logarithm of age at onset of disease led to the conclusion that an individual patient typically has not only two or three but six more rare independent risk factors ${ }^{3}$ that might, however, become balanced by beneficial factors. Diverse aspects are currently attracting interest: aberrant protein aggregation, and possible relations with human endogenous retroviruses (HERVs) and with metals/toxicants, respectively.

\section{Retroviruses and Melanin}

In the patients, HIV or HTLV-1, exogenous counterparts of HERVs, were identified in rare instances. Unfortunately anti-retroviral therapy proved helpful only with exogenous viruses, not in the frequent cases with expression of HERVs ${ }^{4}$. We previously suggested a role for HERVs in melanoma and in multiple sclerosis via an altered biosynthesis of melanin of the skin and, though hypothetical, of neuromelanin, respectively ${ }^{5,6}$. Melanins incorporate metal ions and toxicants ${ }^{6}$. Could it be that a hypothetical altered neuromelanin with increased storage capacity, in particular in the locus coeruleus, is of key-importance in SMND?

A number of risks for SMND/ALS have been described $^{2,7}$, however, observations are often based on only small numbers of patients, confirmation of results by independent studies is largely lacking and, studying multiple endogenous and environmental factors in parallel, the significance of the observations is lost when applying correction for multiple testing. Moreover, there is a high input of speculation by interpretation of the observations towards relations to underlying factors. In the following an attempt is made to develop a hypothesis for the etiology of the disease based on the findings on expression of HERVs and on observational studies.
Environmental Risks for SMND/ALS in Particular Hypothetical Toxicants

Melanin biosynthesis can be disturbed not only by HERVs but also by nicotine ${ }^{8}$ that might contribute, in particular when consuming had begun already early in life, although irrespective of stopping its use later ${ }^{1,2}$. Already physiological neuromelanin is accumulating metals (lead, mercury, iron) and, metal works (welding etc.) have been described as a risk factor ${ }^{1,2}$. Natural neuromelanin has also paramagnetic properties due to its content of iron ${ }^{6}$ and might account for a vulnerability to electric shock and eventually even to extremely low-frequency electromagnetic fields ${ }^{1,2}$. A quantitative reduction of neuromelanin could be helpful as is a feature of Parkinson's. This might explain why co-morbidity with that disease is prolonging the lifetime of patients with $\mathrm{ALS}^{1}$. Strong psychophysical stress is supposed to open the blood-brain barrier of the locus coeruleus for metals and toxicants 9 . This might explain an apparently higher disease risk in military service and professional sports such as soccer, with increased risk related in particular to injuries of the head ${ }^{1,2}$. Toxins, toxicants and supposed precursors can or could have leading roles. Geographic foci with an up to 100fold higher incidence of the disease have been identified in parts of Japan, Guam, and South West New Guinea and a neurotoxic non-proteogenic amino acid, beta-methylamino-L-alanine that is produced by symbiotic cyanobacteria living in the roots of Cycas micronesia has been identified to enter the diet of persons living in these foci ${ }^{1}$. Although this observation clearly points to a relevance of toxins/toxicants, it seems that this is specific only for a quite small number of patients. In some patient pesticides, herbicides and/or insecticides might act as toxic principles ${ }^{1}$. It is, however, questionable whether and, if so, which toxicants or their precursors are present in the diet of the majority of the patients. Nutritional toxicants as well as some beneficial counterparts have possibly shown up in a large study on dietary risks that enrolled over one million men and women; a cohort follow-up was from 1989 to 2002 and found 862 persons who died from $\mathrm{ALS}^{7}$. Could a protective factor be uric acid, a scavenger of nitrosative stress, and a detrimental factor iron? Chicken meat is significantly protective, whereas red meat in which the two factors may be out-balanced shows no influence. Is it possible that beta-carbolines (BC) are dietary factors of critical importance? These euphoria-inducing constituents of coffee are generated upon roasting/heating. Caffeinefree coffee is described as candidate risk factor for $\mathrm{ALS}^{7}$. It must, however, be stated that coffee in general has neither a beneficial nor a detrimental influence, putatively due to outbalancing by a neuro-protective effect of caffeine. Another main source of BC is cigarette smoking that could have a deleterious influence in women ${ }^{1,2}$. Moreover, brown rice/ whole wheat/barley seem to carry likewise a risk ${ }^{11}$; their 
products contain more $\mathrm{BC}$ in comparison with those from their pealed counterparts due to longer cooking/baking. Free $\mathrm{BC}$ can enter the brain, whereas the albumin bound fraction cannot. Albumin binding of $\mathrm{BC}$ requires, however, a unique co-binding of free fatty acids ${ }^{10}$. French fries have been found to correlate inversely with ALS risk ${ }^{7}$, whereas a very low body mass index, in particular in adolescence and young adulthood is carrying a risk to develop the disease later in life ${ }^{1,2}$. Is this reflecting a shortage in free fatty acids in the blood as the underlying risk factor? It must however be emphasized that nutritional BC themselves are not neurotoxic. Most likely inflammation of any origin is contributing, presumably by generation of longer living reactive oxygen species such as hydrogen peroxide. Iron ions stored in the melanin can use it in the Fenton reaction to produce the very short living highly reactive hydroxyl radical $^{6}$ and subsequently might modify $\mathrm{BC}$, that are stored at the same place, to neurotoxins, structurally similar to the experimentally used Parkinson toxin (precursor) methyl4-phenyl-1,2,3,6-tetrahydro-pyridine. Members of the large family of $\mathrm{BC}$ exhibit a broad spectrum of biological activities and can affect multiple central nervous system targets including a modulation of the activity of glutamate transporters via gene activation ${ }^{11}$. These transporters are involved in the action of riluzole, the currently single approved agent with some therapeutic capacity ${ }^{12}$. The still hypothetical neurotoxins are made responsible for a dysfunction of the excitatory system of motor neurons.

\section{Involvement of Metals in the Formation of Aberrant} Proteins

Neuromelanins are also containing proteins, in particular alpha-synuclein, the latter making up about $25 \%$ of the protein content of neuromelanin in dopaminergic neurons ${ }^{13}$. With an increased load of metals within neuromelanin there is a hazard for the formation and subsequent release of pathological forms of proteins. Is this a significant way how aberrant ubiquinated and hyper-phosphorylated DNA binding protein 43 (TDP-43) is formed? A pathological variant of alpha-synuclein is generated in Parkinson's and possibly also in ALS and is forming complexes with SOD- $1^{14}$, causing deposition of aberrant proteins and reducing the amount and functional activity of SOD-1. Accordingly the superoxide anion radical primarily formed in mitochondria is not adequately inactivated and is increasing oxidative and nitrosative stress. This is likewise supposed to be a mechanism in a specific familial form of the disease with mutation and malfunction of mitochondrial superoxide dismutase-1. Superoxide can combine with nitrogen oxide to peroxy-nitrite and with formaldehyde to performic acid, respectively, longer living species and thus effectors of nitrosative and oxidative stress that are more harmful in particular for myelin. Exogenous formaldehyde (one source being cigarette smoking) is also described as a risk factor for $\mathrm{ALS}^{1}$ and, in principle a role might be played even by endogenous formaldehyde that can be formed via methanol from unripe fruits, fresh tomatoes and artificial sweeteners.

Chen et al. ${ }^{15}$ describe the dysfunction in the brain of patients due to a hindered clearance of the detergentresistant ubiquinated and hyper-phosphorylated DNA binding protein 43 (TDP-43), encoded by the already mentioned TARDBP gene. They show that activation of a certain heat shock response results in a dramatic clearance of TDP-43 aggregates that is opening a future therapeutic option $^{16}$. A use of the immune protein interleukin-33, as currently investigated in other neurodegenerative diseases ${ }^{17}$, could become an alternative means to clear such protein deposits of affected motor neurons containing also SOD-1 and alpha-synuclein.

\section{Discussion}

The proposed view on motor neuron disease described here might help to understand risk factors (Table 1 and 2, Figure 1), their roles and their interactions (Figure 2 and 3) and give some rational to revive investigations in methods for stabilization of storage and cautious

\section{$\mathrm{H}_{2} \mathrm{O}_{2}$ hydrogen-peroxide \\ $\mathrm{O}_{2}^{-}$superoxide $\mathrm{ONO}_{2}^{-}$peroxy-nitrite}

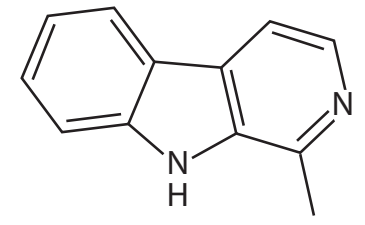

harmane, a beta-carboline

Figure 1: Chemical formulas.

\begin{tabular}{|c|c|c|}
\hline Familial forms, detrimental & Sporadic forms, detrimental & Sporadic forms, beneficial \\
\hline Mutations in SOD-1 gene & Expression of HERV-K & Uric acid \\
\hline Mutations in C9orf72 & Metals (lead, mercury, iron) & Caffeine \\
\hline Mutations in TARDBP & Nicotine & Free fatty-acids \\
\hline & Strong psycho-physical stress \\
\hline & Beta-carbolines \\
\hline & Deficiency in free fatty-acids & \\
\hline
\end{tabular}

Table 1: Detrimental and beneficial underlying risk factors for the development of ALS. 


\begin{tabular}{|c|c|c|}
\hline Familial forms, detrimental & Sporadic forms, detrimental & Sporadic forms, beneficial \\
\hline $\begin{array}{l}\text { Aberrant protein deposits (impairment } \\
\text { of cell functions, apoptosis) }\end{array}$ & $\begin{array}{l}\text { Toxins derived from beta-carbolines (disturbing } \\
\text { iono-trophic glutamate receptors) }\end{array}$ & $\begin{array}{c}\text { Uric acid (inactivating reactive nitrogen species/ } \\
\text { peroxy-nitrite) }\end{array}$ \\
\hline \multirow[t]{4}{*}{ Peroxy-nitrite (demyelination) } & $\begin{array}{c}\text { Inflammation (generation of hydrogen-peroxide, } \\
\text { a reactant in Fenton-reaction) }\end{array}$ & Caffeine (neuroprotective) \\
\hline & $\begin{array}{l}\text { Metals: lead, mercury, iron (Fenton-reaction, } \\
\text { oxidation of beta-carbolines/proteins) }\end{array}$ & $\begin{array}{l}\text { Free fatty-acids (co-binding with beta-carbolines } \\
\text { to albumin) }\end{array}$ \\
\hline & $\begin{array}{l}\text { Aberrant protein deposits (impairment of cell } \\
\text { functions, apoptosis) }\end{array}$ & $\begin{array}{l}\text { Antioxidants (protection against oxidative } \\
\text { stress) }\end{array}$ \\
\hline & Peroxy-nitrite (demyelination) & \\
\hline
\end{tabular}

Table 2: Supposed terminal effectors (and their effects) in the development of ALS.

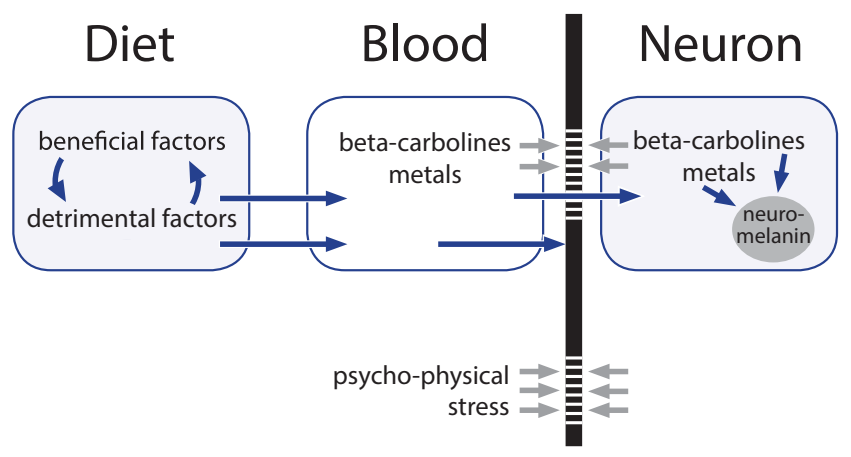

Figure 2: Factors and their way from diet to neuromelanin.

\section{Neuromelanin}

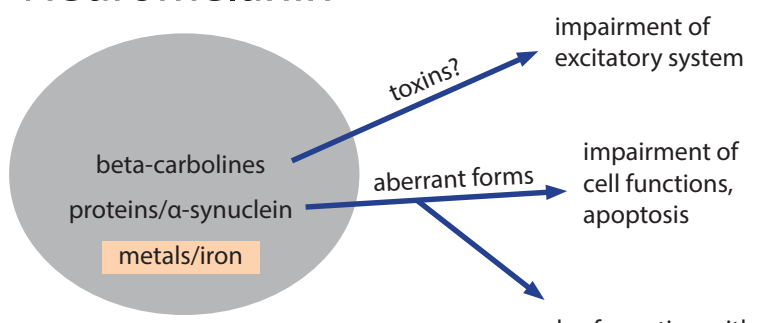

complex formation with SOD-1, increased stress via superoxide, demyelination

\section{Inflammation}

Figure 3: Factors supposed to be released from neuromelanin and their effects.

squeezing out of metals and toxicants from neuromelanin, relying eventually on melatonin ${ }^{18}$, iron chelators ${ }^{19}$, and chloroquine $^{20}$, respectively. Current therapeutic options to revert early disease have been reviewed by Lu et al. ${ }^{12}$ with a focus on mitochondrial protectants, anti-excitotoxic, anti-inflammatory and anti-apoptotic agents. Of benefit are, though apparently only prior to the clinical onset of the disease, antioxidants (vitamin E, tea) ${ }^{7}$. Secondary events in the development of the disease such as invasion/ infiltration of lymphocytes and albumin into the brain are no subjects of this mini review.

\section{References}

1. Zarei S, Carr K, Reiley L, Diaz K, Guerra O, Altamirano PF, et al. A comprehensive review of amyotrophic lateral sclerosis. Surg Neurol Int 2015; 6: 171. Doi: 10.4103/2152-7806.169561.
2. Ingre C, Roos PM, Piehl F, Kamel F, Fang F. Risk factors for amyotrophic lateral sclerosis. Clin Epidemiol. 2015; 7: 181-93. Doi: 10.2147/CLEP. S37505.

3. Al-Chalabi A, Calvo A, Chio A, Colville S, Ellis CM, Hardiman O, et al. Analysis of amyotrophic lateral sclerosis as a multistep process: a population-based modeling study. Lancet Neurol. 2014; 13: 1108-13. Doi: 10.1016/S1474-4422(14)70219-4.

4. Li W, Lee MH, Henderson L, Tyagi R, Bachani M, Steiner J, et al. Human endogenous retrovirus- $\mathrm{K}$ contributes to motor neuron disease. Sci Transl Med. 2015; 7: 307ra153. Doi: 10.1126/scitranslmed.aac8201

5. Krone B, Kölmel KF, Henz BM, Grange JM. Protection against melanoma by vaccination with Bacille Calmette-Guerin (BCG) and/or vaccinia: an epidemiology-based hypothesis on the nature of a melanoma risk factor and its immunological control. Eur J Cancer. 2005; 41: 104-17. Doi: http://dx.doi.org/10.1016/j.ejca.2004.08.010

6. Krone B, Grange JM. Is a hypothetical melanoma-like neuromelanin the underlying factor essential for the aetiopathogenesis and clinical manifestations of multiple sclerosis? BMC Neurol. 2013; 13: 91. Doi: 10.1186/1471-2377-13-91.

7. Morozova N, Weisskopf MG, McCullough ML, Munger KL, Calle EE, Thun MJ, et al.. Diet and amyotrophic lateral sclerosis. Epidemiology. 2008; 19: 324-37. Doi: 10.1097/EDE.0b013e3181632c5d.

8. Yerger VB, Malone RE. Melanin and nicotine: A review of the literature. Nicotine Tob Res. 2006; 8: 487-98. Doi: 10.1080/14622200600790039

9. Pamphlett R, Kum Jew S. Heavy metals in locus ceruleus and motor neurons in motor neuron disease. Acta Neuropathol Commun. 2013; 1: 81. Doi: 10.1186/2051-5960-1-81.

10.Domonkos C, Fitos I, Visy J, Zsila F. Fatty acid modulated human serum albumin binding of the $\beta$-carboline alkaloids norharmane and harmane. Mol Pharm. 2013; 10: 4706-16. Doi: 10.1021/mp400531n.

11.Bharadwaj PR, Bates KA, Porter T, Teimouri E, Perry G, Steele JW, et al. Latrepirdine: molecular mechanisms underlying potential therapeutic roles in Alzheimer's and other neurodegenerative diseases. Transl Psychiatry. 2013; 3:e332. Doi: 10.1038/tp.2013.97.

12.Lu H, Le WD, Xie YY, Wang XP. Current therapy of drugs in amyotrophic lateral sclerosis. Curr Neuropharmacol 2016; 14: 314-21. Doi: $10.2174 / 1570159$ X146661601201522423

13.Xu S, Chan P. Interaction between neuromelanin and alpha-synuclein in Parkinson's disease. Biomolecules 2015; 5: 1122-1142. Doi: 10.3390/ biom5021122

14. Helferich AM, Ruf WP, Grozdanov V, Freischmidt A, Feiler MS, Zondler $\mathrm{L}$, et al. Alpha-synuclein interacts with SOD1 and promotes its oligomerization. Mol Neurodegen. 2015; 10: 66. Doi: 10.1186/s13024015-0062-3

15.Chen HJ, Mitchell JC, Novoselov S, Miller J, Nishimura AL, Scotter EL, et al. The heat shock response plays an important role in TDP-43 clearance: evidence for a dysfunction in amyotrophic lateral sclerosis. BRAIN 2016. pii: aww028. [Epub ahead of print] 
16. Asea AAA, Almasoud NN, Krishnan S, Kaur P (Eds.). Heat shock proteins Vol. 9. Heat shock protein-based therapies. Springer, Cham, Switzerland 2015. Doi: 10.1007/978-3-319-17211-8

17.Fu AKY, Hung KW, Yuen MYF, Zhou X, Mak DSY, Chan ICW, et al. IL-33 ameliorates Alzheimer's disease like pathology and cognitive decline. Proc Natl Acad Sci USA. 2016. Epub ahead of print. Doi: 10.1073/ pnas. 1604032113

18. Weishaupt JH, Bartels C, Pölking E, Dietrich J, Rohde G, Poeggeler B, et al. Reduced oxidative damage in ALS by high-dose enteral melatonin treatment. J Pineal Res. 2006; 41: 313-23. Doi: 10.1111/j.1600079X.2006.00377.x
19. Gal S, Zheng H, Fridkin M, Youdim MB. Restoration of nigrostriatal dopamine neurons in post-MPTP treatment by the novel multifunctional brain-permeable iron chelator-monoamine oxidase inhibitor drug, M30. Neurotox Res. 2010; 17: 15-27. Doi 10.1007/ s12640-009-9070-9

20.D'Amato RJ, Alexander GM, Schwartzman RJ, Kitt CA, Price DL, Snyder SH, et al. Evidence for neuromelanin involvement in MPTPinduced neurotoxicity. Nature. 1987; 327(6120): 324-6. Doi: $10.1038 / 327324 \mathrm{a} 0$ 